\title{
Before and after studies to reduce the gap between road users and authorities
}

\author{
Z. Ebrahim \& H. Nikraz \\ Department of Civil Engineering, Curtin University, Australia
}

\begin{abstract}
The paramount importance of safety for busy urban roads always comes from the responsibility towards protecting the vulnerable road users, who seem to be the victims in most road crashes. Thus, authorities tend to focus on reducing the travelling speed of the vehicles, whereas some road users may consider the move to interfere with mobility. In this paper, a case study of two roads in Perth was conducted to compare two engineering treatments of speed reductions on these two busy shopping strips. The study aim is to illustrate the effect of using the electronic flashing signs rather than the standard signs in terms of speeding reduction and harm minimisation. Crash data were analysed and supported the safety benefits of the electronic flashing signs. In terms of speeding, a ChiSquare analysis showed that there is an association between the engineering treatment type and the three detected speeding levels. Authorities have measured the reduction of the travelling speeds of vehicles and found it to be encouraging. The study found that despite the reduced crashes after the treatments the public seem to show different attitudes to the above safety issue. The study has shown that certain engineering measures can reduce the travelling speed of the vehicles without disturbing mobility. Road users are concerned with delay and other behavioural issue, the results of the questionnaires reveal. There are clear, positive safety benefits from the case study.

Keywords: before and after study, speeding, electronic signs, traffic signs, road crashes, Chi-Square, MANOVA and cluster.
\end{abstract}

\section{Introduction}

In order to reduce travelling speed of vehicles, traffic experts tend to implement lower speed limits on the road. Road users generally think that this may affect 
mobility but authorities focus more towards safety particularly protecting the most vulnerable, the pedestrians, from the lethal speed of vehicles. It has been shown globally that speed limit reduction can contribute to reduce frequencies and severities of crashes. Many researchers around the world have emphasised on one common aim and that is to reduce the speed of the vehicle [1-4]. Researchers also agree that for drivers to comply with a new reduced speed limit, enforcement measures are an essential complementary component. Enforcement is a vital intervention process in restoring road rules that lead to a balance between safety and mobility.

The paper will discuss two sections; the first will focus on a case study between two busy roads to measure the effect of two engineering measures including the effect of speeding enforcement. The other will question the road user's opinion on the new $40 \mathrm{~km} / \mathrm{h}$ speed limit using electronic signs.

The type of detection data used in this paper is the on-the-spot detections which involve all pullovers, including marked/unmarked cars and hand-held detectors, which will be referred to as 'on-the-spot' detection. Traffic Infringement Notices issued at the time of detection will be referred to as (TINs).

\section{Method}

An attempt was made to examine and compare two engineering treatments on two popular roads. Both roads have access to the many businesses, cafes, shops, restaurants and cater for shoppers and diners with a high volume of traffic and pedestrians at different times of the day and night. An electronic sign displaying $40 \mathrm{~km} / \mathrm{h}$ was installed in Beaufort St which is the treated road and is called (Road B). This road has a consistent width of nearly $3.1 \mathrm{~m}$ lane width and the strip is $0.70 \mathrm{~km}$ in length. For Road B, authorities introduced a variable speed zone effective from August 2009. The other road is the compared road and it has standard signs with road markings installed, all displaying $40 \mathrm{~km} / \mathrm{h}$ instead of the previous $50 \mathrm{~km} / \mathrm{h}$. The road is Albany Hwy which is called (Road A) (as shown in Figure 1).

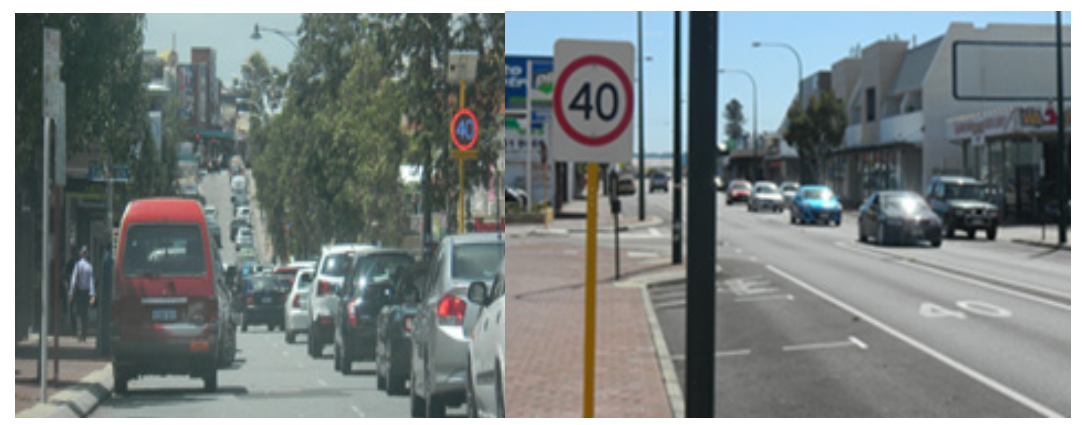

Figure 1: The electronic solar speed sign in road B (left) compared to the standards $40 \mathrm{~km} / \mathrm{h}$ sign and road markings in road A. 


\section{Data}

The study is not based solely on road crashes; therefore data will include other than crash history such as speeding data, including other parameters for both roads. In Table 1 above, collected data are shown such as design parameters, traffic volumes, composition such as commercial vehicle percentages and speed reduction ( $85^{\text {th }}$ Percentile) by Western Australian authorities [5].

Table 1: $\quad$ Data collected for both roads.

\begin{tabular}{|c|c|c|}
\hline Item & Road A (compared ) & Road B ( treated) \\
\hline Existing Design & $\begin{array}{l}\text { Two single Lanes separated with } \\
\text { median or painted median at } \\
\text { different locations with parallel } \\
\text { parking along each side of the } \\
\text { footpath }\end{array}$ & $\begin{array}{l}\text { Two single Lanes separated with } \\
\text { median or painted median at } \\
\text { different locations with parallel } \\
\text { parking along each side of the } \\
\text { footpath }\end{array}$ \\
\hline $\begin{array}{l}\text { Daily traffic volume both } \\
\text { direction (veh/day) between } \\
\text { 2009, 2010 \& 2011 }\end{array}$ & $\begin{array}{c}5500-7500 \\
\text { Fairly consistent }\end{array}$ & $\begin{array}{c}24,000 \\
\text { Fairly consistent }\end{array}$ \\
\hline Road length (km) & 3.2 & 0.70 \\
\hline Lane width(m) & $3-4.2$ & 3.1 \\
\hline $\begin{array}{c}\text { Speed Reduction (85 } \\
\text { Percentile) }\end{array}$ & 3.7 (average of two locations) & 7.65 (Average of both bounds) \\
\hline $\begin{array}{c}\text { Commercial vehicles (\%) } \\
\text { from Council }\end{array}$ & $\begin{array}{c}3-6 \% \\
\text { from site observation }\end{array}$ \\
\hline
\end{tabular}

In terms of the $85^{\text {th }}$ percentile speed of the travelling vehicles on the two roads under study, Table 1 shows that a better reduction rate of speed on Road $B$ compared to that on Road A [5]. The tangible reduction showed the initial benefits of the electronic variable speed signs over the use of the standard signs and the road markings. The scope of this paper is to highlight the benefits of the electronic signs from the road safety perspective in terms of crash reductions and speeding reduction and less excessive speeding; also comparing the attitudes of the road users on these signs.

\section{Analyses}

\subsection{Crashes before and after}

Three general trends are shown in Figure 2 below. They are for the period 19902011. Road A is shown here as the compared road and Road B is the treated road. The intersection is part of the treated road in Road B. The addition of the intersection to Figure 2 is to highlight the low contribution of the intersection to the outcome of the benefits of the $40 \mathrm{~km} / \mathrm{h}$ variable speed zones. This intersection was found to affect the reduction of road crashes as it is not contributing to the crash reductions as the rest of Road B; more details are discussed below. Importantly it can be learned from Figure 2 that the trend in the last five years for road $B$ has been the lowest ever in the last 21 years compared to that of road A. Road A showed lowest recorded crashes in 2003, and 2006 and not recently. Road B has had the lowest crash values in the last five years. 


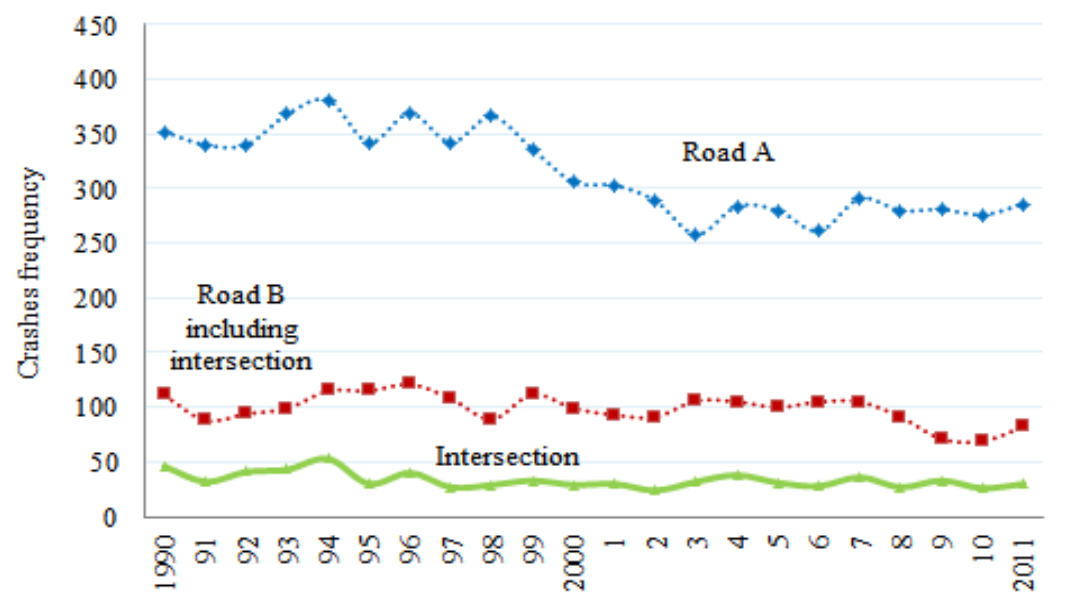

Figure 2: $\quad$ Crashes frequency during 1990 and 2011.

Data was further analysed to compare before and after crash frequency. In Figure 3 below focus is on the before and after study comparison between the two roads. Road A does not show much reduction after the use of the standard $40 \mathrm{~km} / \mathrm{h}$ signs and road marking. Road B showed on average lower crash frequency of the $40 \mathrm{~km} / \mathrm{h}$ electronic signs. This reduction would even be higher had the intersection influence been removed.

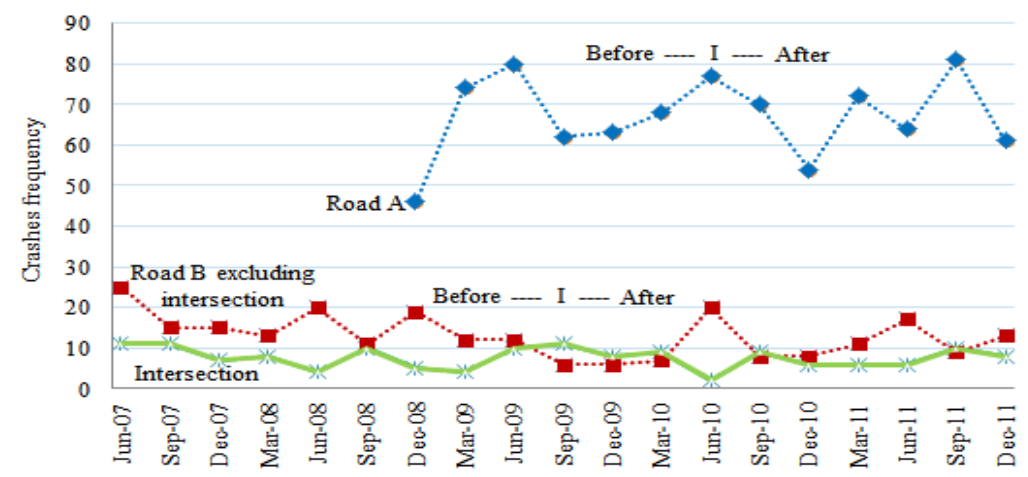

Figure 3: The effect of the electronic sign treatment on reducing excessive speeding levels.

This crash reduction in Road B without the influence of the intersection would have improved the crash reduction by a further 7\% (as shown in Table 2). In fact, analysis showed that Road B has zero severity crashes without the influence of the intersection. This is considered vital in terms of KSI (killed or severely injured). Pedestrian crashes were also reduced by $20 \%$ since the 
installation of the electronic signs in Road B. Careful interpretations need to be taken into consideration of the pedestrian results for two reasons. Firstly the low number of pedestrian injuries would make it difficult to come to firm conclusions and secondly there need to be more data. The study found that long term crash trend seems to be contributing to the reduction of crashes in the all three entities (Road A, Road B and the intersection of Road B; this is shown in Table 2. The long term crash trend would still leave Road B with reasonable reduction that may override regression to the mean. A phenomena that occurs particularly when high number of crashes may regress towards the mean of that particular road at a later stage [6]. The 18\% reduction of total crashes achieved in Road B may be considered high enough to cater for such phenomena. According to [7], three years or more are required for before and after to alleviate the regression to the mean effect. In the case of Road B, data used are less than three years but the crash reduction is still considered high. Crash reduction may be due to chance if not large and if it is large then it could be attributed to the treatment $[6,8]$. The data below also may highlight the importance of improving the design and traffic movement of the intersection of road B.

Table 2: $\quad$ Crash reductions and trends.

\begin{tabular}{|l|c|c|c|c|}
\hline \multicolumn{1}{|c|}{ Location } & $\begin{array}{c}\text { Total crashes } \\
\text { reduction } \\
\%\end{array}$ & $\begin{array}{c}\text { Pedestrian crashes reduction } \\
\%\end{array}$ & $\begin{array}{c}\text { Injury } \\
\text { reduction } \\
\%\end{array}$ & $\begin{array}{c}\text { Crash } \\
\text { trend } \\
\%\end{array}$ \\
\hline Road A & -7 & -20 & -10 & -18 \\
\hline Road B & -18 & +86 & -10 & -9 \\
\hline $\begin{array}{l}\text { Intersection of } \\
\text { Road B }\end{array}$ & -7 & Few only & +200 & -16 \\
\hline
\end{tabular}

\subsection{Speeding before and after}

Statistical analyses were employed using Chi-Square to establish if there is an association between the three speeding levels (less than $9 \mathrm{~km} / \mathrm{h}$ above the speed limit, between $10 \mathrm{~km} / \mathrm{h}$ and $19 \mathrm{~km} / \mathrm{h}$ above the speed limit and $20 \mathrm{~km} / \mathrm{h}$ and more above the speed limit) and the type of treatment on the two roads. After controlling the hourly rate per month using an on-the-spot detection type of enforcement, a Chi-square test of independence indicated a significant association between the type of treatment on Roads A and B and the three levels of speeding (as shown in Figure 4 ), where, $X^{2}(2, n=1342)=29.38, p=.001$. It can also be seen as the speed violation level gets higher, Road A showed less affect by the treatment of the standard signs compared to Road B with the electronic flashing speed signs. This is clear except for the lowest speed violation level.

It was thought appropriate to compare the before and after of drivers' speeding behaviour of the treated road B. A Chi-Square analysis revealed that there was an association between the after speeding levels and the TINs detected. Where $X^{2}(3, \mathrm{n}=1175)=81.02, p=.001$. It showed that $p$ value is $0.001<0.005$. We reject the null hypotheses that speeding levels and treatment periods (before and after) are independent. Therefore, there is an association between the treatment and its effect on speeding behaviour. Hence a lower number of TINs 


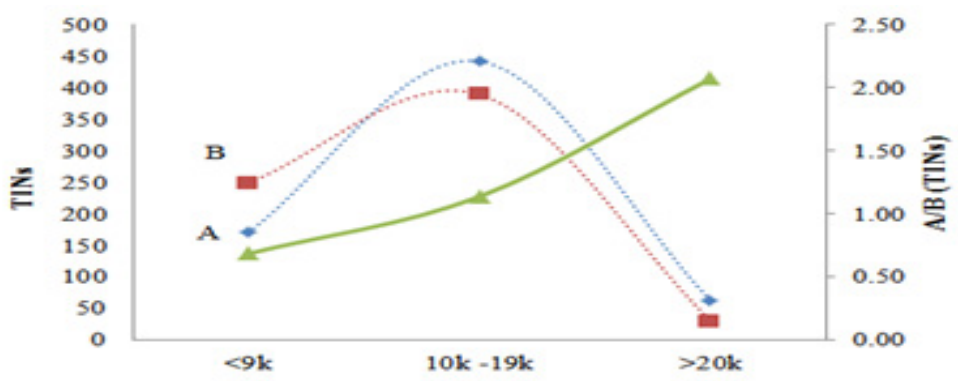

Figure 4: The effect of the electronic sign treatment on reducing excessive speeding levels.

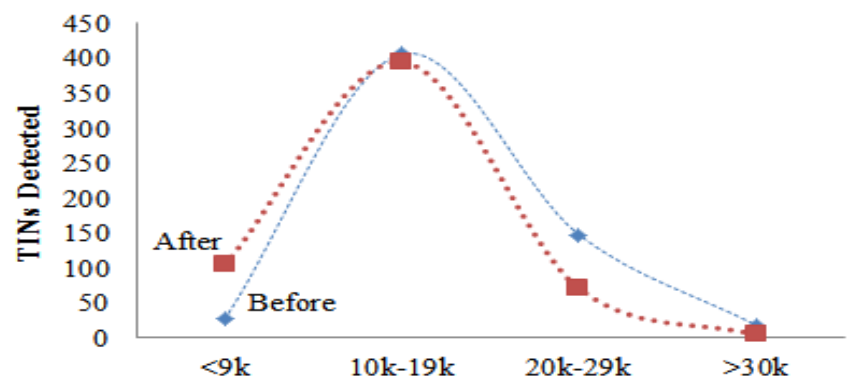

Figure 5: Unified hours of exposure for before and after 'on the spot' detection using the electronic solar speed signs in Road B.

were detected at higher speeding levels in the after period compared to the before period. Thus, the electronic sings are contributing to safer speeding levels, particularly low TINs at the high and extreme speeding levels (as shown in Figure 5).

\subsection{Attitude on Road B}

Despite the above positive indicators on the electronic $40 \mathrm{~km} / \mathrm{h}$ signs, the attitudes of road users remain different. The overall mean response rates for the delay concerns during the day were $74 \%$ [9]. This indicates the elevated drivers' concern about the issue of delay rather than the safety benefits of the electronic signs. A question was asked to four cultural groups of Perth as to whether drivers think that delays are due to a $40 \mathrm{~km} / \mathrm{h}$ limit during the day rather than the traffic signals. Data was further examined searching for significant differences of groups by performing MANOVA. Results indicate that there was statically significant difference between the groups on the combined dependent variables. $F(15,806)=4.2, p=.000$, Wilks' Lambda $=.81$; partial eta square $=.07$. The item reach statistical differnce using Bonferroni adjusted alpha level of .010.” An inspection of the mean response rates indicated that European group recorderd 
the lowest mean response rate and it was statistically different and much lower than the African mean response rates. When average linkage between the groups was performed, cluster analysis revealed that European group was clearly separated from the rest of the clustered groups (see Figure 6). In the meantime, the Dendogram in Figure 6 shows that the Australian group is in a common cluster with the Asian and the African groups.

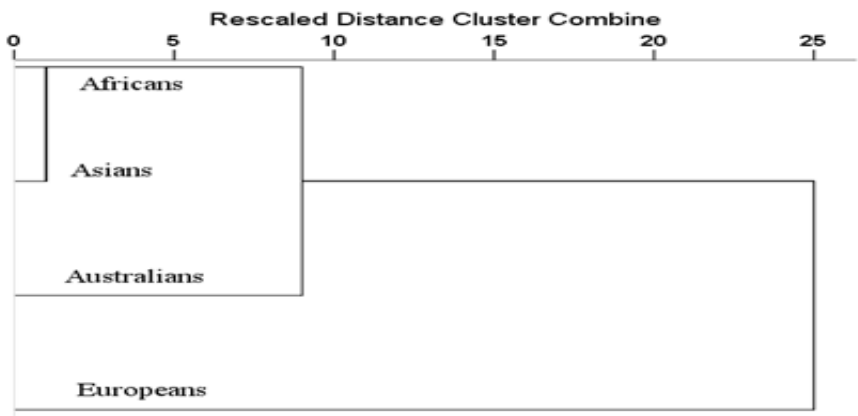

Figure 6: Dendogram of four cultural road users groups.

\section{Discussions}

The challenge in balancing between safety and mobility is a known concern for road authorities. The preference of protecting pedestrians and delaying drivers may need to be accepted by the road users as crashes are reduced. This is more tangible on busy urban roads where separation of pedestrians from vehicles is not possible. There was a lot of evidence in this paper to suggest that the installation of the electronic $40 \mathrm{~km} / \mathrm{he}$ signs were positive. In fact even with the use of the same signs somewhere else in trial, the Authorities believe that these initial findings have shown that electronic speed signs, which are used on Road $B$, seem to be effective devices in reducing speeds of the travelling vehicles [10]. The dilemma is clear, the public is concerned with delay; at the same time there are clear, positive benefits from the case study that can contribute to safety and enhance mobility by regulating traffic with less crash disturbances.

The vital two questions to be asked in this discussion are: what is to be learned from the above findings? and what direction to follow? The answer to the first question is that the new reduced safe speed has benefits and the (+ve) aspect may need to be highlighted, especially if it is successful elsewhere (such as the +ve of these electronic variable speed signs demonstrated in 18 of Melbourne's busiest strips shopping centres). Following the successful trial of these $40 \mathrm{~km} / \mathrm{h}$ reduced speed limits, more shopping strip zones are gradually being introduced to these signs [11] and the same was confirmed recently in [12]. Similarly, the Toronto authorities are adopting $40 \mathrm{~km} / \mathrm{h}$ for areas with busy pedestrian movements and $30 \mathrm{~km} / \mathrm{h}$ for most residential streets [13]. 
In addition to that, the European Parliament is currently calling for speed limits on residential roads and single-lane roads to be reduced to $30 \mathrm{~km} / \mathrm{h}$ without cycle tracks throughout the European community in the interests of road safety. That would equate to $20 \mathrm{~m} / \mathrm{h}$ in the UK and the move has been welcomed by the campaign group "20's plenty for us”, which lobbies for that limit to be put in place [14]. In fact, $20 \mathrm{~m} / \mathrm{h}(32 \mathrm{~km} / \mathrm{h})$ speed limits have already been introduced in a number of cities in Britain including Bristol and Liverpool.

The answer to the second question is to highlight the (-ve) aspect of the old unsafe speed that may need to be highlighted in the same manner if not in more magnitude, particularly if the success elsewhere is not available through literature, then the -ve aspect needs to highlighted and strongly publicised. An example of that is the recent call by Curtin-Monash Accident Research Centre for the $30 \mathrm{~km} / \mathrm{h}$ limit to be tested near shopping centres, hospitals and schools as pedestrian fatalities have risen in roads with $60 \mathrm{~km} / \mathrm{h}$ limits [15]. In Toronto, there is evidence to suggest that both cyclists and pedestrians are far less likely to be killed for every $10 \mathrm{~km} / \mathrm{h}$ reduction below $60 \mathrm{~km} / \mathrm{h}$ [13].

In terms of enforcement, a recent communication between the European Commission and the European Parliament, the second key objective recommended for the next decade is to increase enforcement of road rules. It added that enforcement remains a key factor in increasing the conditions for a considerable reduction in the number of deaths and injuries, especially when it is intensively applied and widely publicised [16].

To conclude, it is essential to sustain safe roads by including enforcement which is a crucial and tangible element to monitor, regulate and sustain safe speed. Therefore, the cycle of developing safe speeding culture must also continue (as shown in Figure 7).

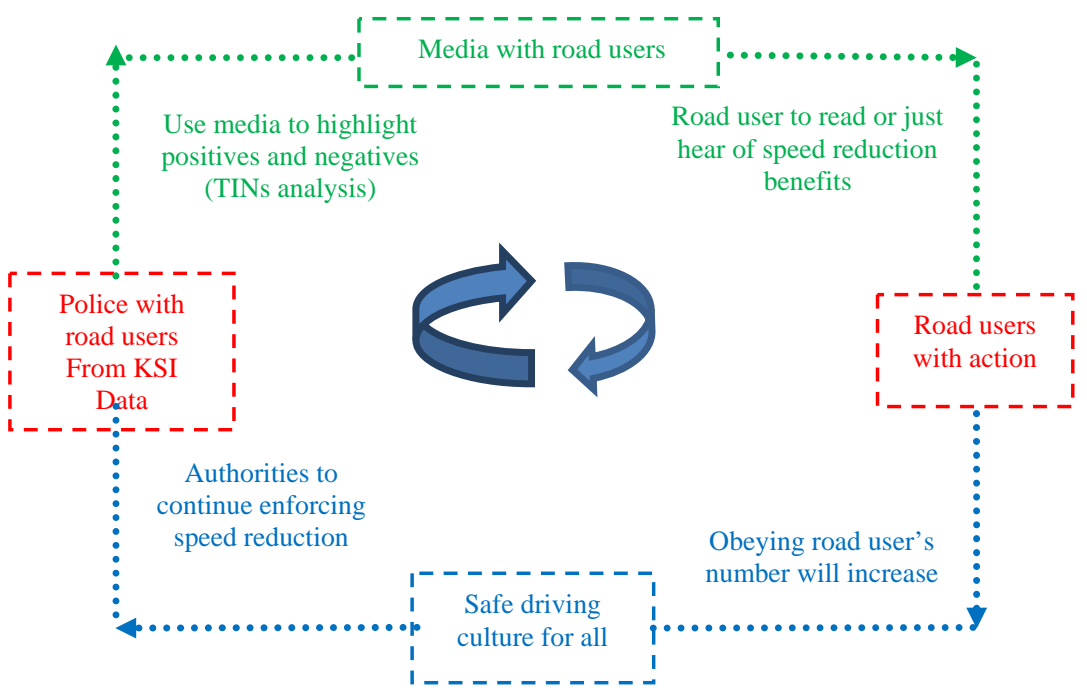

Figure 7: $\quad$ Examining sustainability towards zero pedestrian fatalities. 


\section{Limitations}

Limited data availability was of concern in the before and after period in terms of crashes and speeding data; a longer period may confirm stronger reliability results. Road A came into effect later than road B which is why data was limited in terms of crashes and speeding.

\section{Acknowledgements}

We would like to thank Ms Chris Canny, the Assistant Director of the Academic Development of the WA Police, for her valuable support and acknowledgement of this paper. Thanks to the Academic Research Administration Unit of the WA police for supplying the data and clarifying labelling and other data inquiries. We are also indebted to Thandar Lim of Main Roads WA for making available the roads' crash data.

\section{References}

[1] Mohan, D., Traffic safety: International status and strategies for the future. World Automotive Summit, FISITA, 2010.

[2] Preusser, D., Wells, J., Williams, A. and Weinstein, H. 'Pedestrian crashes in Washington, DC and Baltimore’ Accident Analysis and Prevention, (34), pp. 703-710.2002.

[3] Oxley, J. A., Diamantopoulou, K, and Corben, B.F. Injury reduction measures in areas hazardous to pedestrians. Stage 2, Countermeasure Evaluation. Report 178, Monash University, 2001.

[4] DOT, "Literature Review on Vehicle Travel - Speeds and Pedestrian Injuries”. Final Report, National Highway Traffic Safety Administration. 1999.

[5] Main Road, WA, Australasian Road safety. Research, Policing and education, conference, Perth, 2011.

[6] Michaels, M. R., Two simple techniques for determining the significance of accident- reducing measures. Traffic Engineering, (12) 36, pp. 45-48, 1966.

[7] Sharma, S. L. and Datta, T.K., Investigation of Regression to mean effect in traffic safety evaluation methodologies. Transport Research Record, pp. 32-39, 2007.

[8] Hauer, E., Observational before-after studies in road safety. Estimating the effect of highway and traffic engineering measures on road safety. Pergamon.UK, 2002.

[9] Ebrahim, Z. and Nikraz, H., Examining Attitudes towards safe speed to protect pedestrians. International Journal of Transportation Science and Technology, (4). pp. 319-334, 2012.

[10] Thomas, B., Speeds curb trials to continue, The West Australian January 30, 2012. 
[11] Vic Roads. Official web page. $\underline{\text { www.vicroads }}$ vic.gov.au /Home/SafetyAndRules/SafetyIssues/Speed/VictoriasSpeedLimits.htm.2012

[12] Wright, A., $40 \mathrm{~km} / \mathrm{h}$ speed limit to boost road safety in CBD, Herald sun. $15^{\text {th }}$ May.2012.

[13] Moran, A, Report lower speed limits by as much as $20 \mathrm{~km} / \mathrm{h}$ Toronto. http://digitaljournal.com/article/323583\#ixzz1vPsSSIOa, 24th April. 2012.

[14] MacMichael, S., MEPs push for 30kph (18.641mph) limit on residential roads throughout Europe, 2011. Junehttp://road.cc/content/news/37947meps-push-30kph-18641mph-limit-residential-roads-throughout-europe. 2012.

[15] O'Connell, R., Road safety expert calls for $30 \mathrm{~km} / \mathrm{h}$ limit trials. The West Australian, February 7, 2012.

[16] EC, Towards a European road safety area: policy orientations on road safety 2011-2020SEC (Communication from the Commission of the European parliament, Council, the European Economic and Social Committee of the Regions). Brussels, 2010. 